\title{
Temporal and between-site variation in helminth communities of bank voles (Myodes glareolus) from N.E. Poland. 1. Regional fauna and component community levels
}

\author{
J. M. BEHNKE ${ }^{1 *}$, A. BAJER ${ }^{2}$, P. D. HARRIS ${ }^{1}$, L. NEWINGTON ${ }^{1}$, E. PIDGEON ${ }^{1}$, \\ G. ROWLANDS ${ }^{1}$, C. SHERIFF ${ }^{1}$, K. KULIŚ-MALKOWSKA ${ }^{2}$, E. SIŃSKI ${ }^{2}$, F. S. GILBERT ${ }^{1}$ \\ and C. J. BARNARD ${ }^{1}$ \\ ${ }^{1}$ School of Biology, University of Nottingham, University Park, Nottingham NG7 2RD, UK \\ ${ }^{2}$ Department of Parasitology, Institute of Zoology, University of Warsaw, ul. Miecznikowa 1, 02-096 Warsaw, Poland
}

(Received 19 February 2008; revised 19 February and 5 March 2008; accepted 5 March 2008)

\section{SUMMARY}

Helminth infections were studied in bank voles (Myodes glareolus) from 3 woodland sites in N.E. Poland in the late summers of 1999 and 2002, to assess the temporal stability of derived statistics describing the regional helminth fauna and component community structure, and spatial influence on the latter. Regional helminth fauna changed dramatically between the two years, primarily due to a fall in the abundance of Syphacia petrusezwiczi but was partially compensated for by an increase in Mesocestoides lineatus and Cladotaenia globifera. It was dominated by nematodes overall, but more so in 1999 than in 2002 when larval cestodes were more frequent. Most derived parameters for component community structure varied considerably between sites and the two surveys, the hierarchical order for sites not being maintained between surveys. They were susceptible to the disproportionate influence of three relatively rare, unpredictable species with the greatest overall aggregated distribution among hosts. Jaccard's similarity index was less influenced by the rare species, showing greater stability between sites and across years. In conclusion, temporal variation confounded any site-specific characteristics of the summary measures quantified in this study and their usefulness is therefore restricted to the years in which the surveys were conducted.

Key words: helminths, bank vole, Myodes glareolus, Clethrionomys, regional helminth fauna, component communities, site-specific variation.

\section{INTRODUCTION}

The study of helminth parasite communities in small wild mammals has attracted a lot of attention over the years, and at the heart of the on-going debate is the uncertainty about the degree to which these communities are structured, interactive or isolationist, stable or ephemeral (and therefore the extent to which they are predictable) and the relative importance of the factors that contribute to variation in community structure (Montgomery and Montgomery, 1990; Poulin, 1997, 2007). Typically, hierarchical arrangements characterize helminth communities (Esch et al. 1990; Poulin, 2004) and to some extent structure, stability and predictability depend upon the level of organization that is considered. However, the extent to which the derived parameters reflecting the characteristics of each community at each level of organization can vary

* Corresponding author: School of Biology, University of Nottingham, University Park, Nottingham NG7 2RD, UK. Tel: +44 (0) 115951 3208. Fax: + 44 (0) 115951 3251.E-mail: jerzy.behnke@nottingham.ac.uk temporally or spatially has seldom been evaluated comprehensively through empirical studies (Hartvigsen and Kennedy, 1993; Timi and Poulin, 2003; Calvete et al. 2004). Despite the wealth of publications on helminths of rodents, there are few studies that tackle these issues satisfactorily (Kisielewska, 1970a,b; Haukisalmi et al. 1987; Montgomery and Montgomery, 1989, 1990; Tenora and Stanek, 1995).

At the highest level of organization is the total helminth fauna of a given species of host across its entire geographical range (Poulin, 1997). Most often, however, animals are sampled on a smaller geographical scale and, based on pooled data derived from different populations of hosts sampled from a range of sites within the defined region, the regional helminth fauna form the next level of organization. Helminths encountered in populations of hosts within any region constitute component communities, and these in turn are comprised of infracommunities represented by all the parasites within individual hosts. Each level of organization is subject to different evolutionary and ecological pressures, 
and the degree to which derived parameters used to describe communities vary/show temporal and/or spatial stability will depend on the particular organizational level (Poulin, 1997).

Since infracommunities are the shortest lived, corresponding to a fraction of the life-time of their host, we may expect these to be the most dynamic, showing the greatest spatial and temporal variation. In the case of bank voles, Myodes glareolus, infracommunities may last just a few months in the summer period, although autumn-born voles live longer and each year sufficient individuals survive through the long winter to repopulate the woodland habitats in the following spring (Pucek et al. 1969; Alibhai and Gipps, 1985). Component communities are presumed to be longer lived (between several and many host life-times, depending on the stability of the particular population), and therefore intuitively might be expected to be more predictable. Changes at this level depend primarily on colonization events introducing new species to the population of hosts, or extinction through loss of transmission potential. The regional parasite fauna should be even more stable, cushioned against excessive temporal variation by the large number of component communities, temporally and spatially linked to differing extents, which are included within it. Most stable of all should be the total helminth fauna of the host species across its entire geographical range, which can change only through evolutionary events such as the capture of new helminth species through host switching or the allopatric subdivision of parasite lineages through host isolation. These processes commence initially within infracommunities and, if they persist these can spread through component communities to eventually feed over time into regional helminth communities and the total helminth fauna of the host.

Helminth component communities are known to vary in composition, species richness, prevalence etc. between populations of hosts living in sites which may be quite proximal to one another, and in some cases these variations have been linked to differences in habitat quality (Montgomery and Montgomery, 1990; Abu-Madi et al. 2000; Calvete et al. 2004; Behnke et al. 2004; Eira et al. 2006). In other cases, however, marked variation in component communities has been found in rodents living in virtually indistinguishable habitats (Behnke et al. 2001). But, are such differences between sites maintained over years or are they ephemeral, and if so over what time scale do they vary? Is the rank order of measures of community structure stable over the short/medium/long-term or does it change unpredictably across component communities that are spatially distant? Are predictability or change properties of regional, component or infracommunities? There are very few long-term studies in this field that adequately address these issues (Montgomery and Montgomery, 1990).

In our earlier work we found that the helminth infracommunities of bank voles were characterized by medium-term stability in a woodland site in N.E. Poland (Bajer et al. 2005). Based on a study conducted in 1999, we also reported detectable and quantifiable differences in community structure of helminths in voles living in 3 semi-isolated woodland habitats in the same region (Behnke et al. 2001). We re-examined each of these populations in 2002, sampling at the same time of year as in the original study to avoid seasonal factors. Over evolutionary time these three individual subpopulations of voles constitute part of a continuum across the western Palaearctic region to which bank voles are indigenous (Corbett, 1978; Spitzenberger, 1999), and by pooling data on helminth infections from all three sites, the derived summary statistics reflect the local helminth fauna of the Mazury region in Poland. Although bank voles can colonize unoccupied territory at the rate of $2-4 \cdot 5 \mathrm{~km}$ year ${ }^{-1}$ given suitable continuous habitat (Smal and Fairley, 1984), their dispersal distance is generally much shorter (Gliwicz and Ims, 2000) and even closely located populations differ genetically (Aars et al. 1998; Gerlach and Musolf, 2000) suggesting that mixing is neither frequent nor extensive in the short term. It is therefore unlikely that there had been any substantial or frequent exchange of individuals between the three woodlands in our study during ecological time because of lack of connectivity between the woods (Van Apeldoorn et al. 1992): they are too distant from one another and are separated by substantial barriers (lakes, canals and open pasture/cultivated land; see Behnke et al. 2001) that impede the movement of voles. In ecological time each of these essentially represents a semi-isolated population of hosts, and therefore, summary statistics for helminth infections of voles from each location at this intermediate level reflect helminth component communities of different host populations within the region.

Here we first assess how the regional parasite fauna has changed between the two surveys and then quantify the extent to which between-site differences in component community structure are confounded by temporal effects. Given the above discussion concerning our expectations of stability at the regional and component community levels, our null hypothesis is that the regional helminth fauna and helminth component communities in wild bank voles living in semi-isolated sites within the region, are generally predictable and relatively unchanging in the medium term (2-5 years or so), despite the evident within-year seasonal effects, and the expected age-effects on individual infracommunities. In the accompanying paper we consider effects on infracommunities (Behnke et al. 2008). 
MATERIALS AND METHODS

\section{Study sites}

The study sites were located in Mazury in the north eastern corner of Poland, in the vicinity of Jezioro (Lake) Śniardwy and the towns of Mikołajki, Ryn and Pisz as described comprehensively by Behnke et al. (2001). Site 1 is referred to as Urwitalt (N $53^{\circ} 48 \cdot 153$, EO $21^{\circ} 39 \cdot 784$ ), Site 2 as Talty (N $53^{\circ} 53 \cdot 644$, EO $\left.21^{\circ} 33 \cdot 049\right)$ and Site 3 as Pilchy (N $53^{\circ} 42 \cdot 228$, EO $\left.21^{\circ} 48 \cdot 499\right)$ after nearby settlements.

\section{Voles}

In this paper we refer to bank voles as Myodes glareolus following the recent recommendations that Myodes rather than Clethrionomys is the valid name for this genus of rodents (Wilson and Reeder, 2005; Carleton et al. 2003). The methods used for trapping rodents, for sampling and processing trapped animals and establishing age categories have all been fully described in Behnke et al. (2001).

\section{Measures of community structure}

Measures of component community structure were identical to those used by Behnke et al. (2001), following Kennedy and Hartvigsen (2000). The total number of helminth species, the Berger-Parker Dominance Index and the unbiased Simpson's Index of Diversity (ID) for each site in each year and on pooled data are given. In some analyses we have excluded $S$. petrusewiczi, and in others this species as well as the 2 larval cestodes, M. lineatus and $C$. globifera, are excluded because these three species can cause extremely high infections, numbering several hundred/thousand worms, despite an overall low prevalence in the population. We tested the idea that these species, in particular, exert a disproportionate influence on indicators of community structure, and we compared values with and without these species.

Similarity between sites and in different years was compared by Jaccard's and Sale's Similarity Indices for the latter following Montgomery and Montgomery (1990) using:

$\mathrm{C}_{\mathrm{ij}}=1-0 \cdot 5 \sum_{k}^{s}\left|\mathrm{p}_{\mathrm{ik}}-\mathrm{p}_{\mathrm{jk}}\right|$,

where $\mathrm{C}_{\mathrm{ij}}$ is the proportional similarity between surveys $i$ and $j$, and varies from 0 to $1 . \mathrm{p}_{\mathrm{ik}}-\mathrm{p}_{\mathrm{jk}}$ are the proportions of the total helminth fauna at each survey comprising the $k$ th species and $s$ is the number of species. The sign of $p_{i k}-p_{j k}$ is converted to positive before summing.

\section{Statistical analysis}

The statistical approach adopted has also been documented comprehensively in the earlier publications (Behnke et al. 2001; Bajer et al. 2005).
Prevalence data (percentage of animals infected with all helminths) are given with $95 \%$ confidence limits, calculated as described by Rohlf and Sokal (1995) employing bespoke software. The distribution of voles, among age and sex classes and in relation to different sites and the years of the surveys, and prevalence of infection with all helminths combined were analysed by maximum likelihood techniques based on log linear analysis of contingency tables using the software package SPSS (version 12.0.1). Full factorial models incorporated the intrinsic factors age (3 age classes) and sex (2 levels, males and females) and the extrinsic factors site (3 levels) and year of survey (2 levels, 1999 and 2002). Infection was considered as a binary factor (present/absent). Beginning with the most complex model, involving all possible main effects and interactions, those combinations that did not contribute significantly to explaining variation in the data were eliminated in a stepwise fashion beginning with the highest-level interaction. A minimum sufficient model was then obtained, for which the likelihood ratio of $\chi^{2}$ was not significant, indicating that the model was sufficient in explaining the data. The importance of each term (i.e. interactions involving infection) in the final model was assessed by the probability that its exclusion would alter the model significantly and these values are given in the text.

We used Taylor's Power Law (Taylor, 1961) to identify species of helminths that showed most variation and hence less predictability. The logarithms of mean abundance and variance (of abundance) were calculated separately for each of the 3 sites and in the 2 years of the surveys for each of the 7 most prevalent species of helminths recorded, and when prevalence was zero, those cells were excluded. The line graphs were fitted in Microsoft Office Excel 2003 (by least squares methods) and the statistical analysis of the regression of log transformed variance on abundance was carried out in SPSS version 12.01 for Windows.

\section{RESULTS}

\section{Myodes glareolus}

In total, 358 bank voles were sampled from the 3 study sites: 139 in 1999 and 219 in 2002. The structure of the sampled host population by year, site and age is summarized in Table 1.

The numbers of voles examined from the 3 sites did not differ significantly in respect of the 2 sexes. However, the distribution of voles among the 3 age groups varied both between sites $\left(\chi^{2}{ }_{4}=13 \cdot 0, P=\right.$ $0 \cdot 011)$, and between years $\left(\chi_{2}^{2}=6 \cdot 8, P=0 \cdot 033\right)$. As expected, voles in age class 2 formed the largest proportion of the sampled animals from all 3 sites $(42 \cdot 9,46 \cdot 5$ and $40 \cdot 2 \%$ for Urwitałt, Tałty and Pilchy respectively). The youngest age class was least 
Table 1. Numbers of Myodes glareolus examined by year of survey, site and host age

(Statistical analysis: The minimum sufficient model was site $*$ age class + year $*$ age class $\chi_{24}^{2}=28 \cdot 8, P=0 \cdot 227$.)

\begin{tabular}{llrrrrr}
\hline \hline & & \multicolumn{3}{l}{ Age class } & & \\
\cline { 3 - 5 } Site & Year & 1 & 2 & 3 & $\begin{array}{c}\text { Total } \\
\text { by year }\end{array}$ & $\begin{array}{c}\text { Total } \\
\text { by site }\end{array}$ \\
\hline Urwitałt & 1999 & 3 & 23 & 14 & 40 & \\
& 2002 & 15 & 25 & 32 & 72 & \\
Tałty & Combined & 18 & 48 & 46 & & 112 \\
& 1999 & 11 & 21 & 9 & 41 & \\
Pilchy & 2002 & 23 & 32 & 18 & 73 & 114 \\
& Combined & 34 & 53 & 27 & & \\
Total by year & 1999 & 22 & 26 & 10 & 58 & \\
& 2002 & 19 & 27 & 28 & 74 & \\
Total by age & Combined & 41 & 53 & 38 & & \\
TOTAL & 1999 & 36 & 70 & 33 & 139 & \\
\hline \hline
\end{tabular}

represented at Urwitalt $(16 \cdot 1 \%$ of voles from this site), but formed a similar percentage at Talty and Pilchy (29.8 and $31 \cdot 1 \%$ respectively) and conversely the oldest voles were best represented at Urwitalt $(41 \cdot 1 \%)$, and approximately equally at Tałty $(23 \cdot 7 \%)$ and Pilchy $(28 \cdot 8 \%)$. Overall, with sites combined, the youngest age class was similarly represented in both years of the study $(25.9 \%$ and $26.0 \%$ in 1999 and 2002 respectively), although there were differences between the sites. In 1999 age class 2 voles comprised a larger percentage of the catch compared to 2002 (50.4\% and $38.4 \%$, respectively) and accordingly age class 3 voles were more common in $2002(23.7 \%$ and $35.6 \%$, respectively).

\section{Changes in the regional helminth community structure with time}

Quantitative changes. In total, combining all 3 sites and both years, 13501 helminths were recovered, but there was a substantial reduction $(71.8 \%)$ in the total number of helminths recovered between 1999 (10 529) and 2002 (2972) even though more voles were sampled in 2002 (Table 1). When sample size was taken into consideration the reduction was even more marked $(82 \cdot 1 \%$; mean in $1999=75.7$ and in $2002=13 \cdot 6)$. This change between years was predominantly due to $S$. petrusewiczi which accounted for $70 \cdot 5 \%$ (9516) of all the worms recovered, but which declined in abundance substantially between the 2 surveys (Behnke et al. 2008). Without $S$. petrusewiczi and with sample size taken into consideration, helminth burdens declined moderately (by $13.5 \%$; mean number of helminths in $1999=12 \cdot 1$ and in $2002=10 \cdot 5)$.
Two other species had a marked effect on the total number of helminths recovered: Mesocestoides sp. and $C$. globifera, both of which are relatively infrequent but when present, often number in hundreds. Without these species, and without S. petrusewiczis and with sample size taken into consideration, the remaining total worm burdens changed more markedly (totals of worms recovered $=1547$ in 1999 , and 1388 in 2002 and means $=11 \cdot 1$ and $6 \cdot 3$ respectively). The change represented a reduction of $43 \cdot 0 \%$, mainly attributable to these species increasing abundance in 2002 (when $460 \mathrm{M}$. lineatus and $450 \mathrm{C}$. globifera were recovered, compared with 140 and zero, respectively in 1999).

Two hundred and ninety one voles $(81 \cdot 3 \%$, [77.7-85.6]) carried at least 1 species of helminth $(85 \cdot 6 \%$ [79.3-90.9] in 1999 and $78 \cdot 5 \%$ [73.1-84.0] in 2002). The difference between years was not significant (with site, age and sex taken into account, log-linear model, year $*$ presence/absence of helminths $\left.\chi^{2}{ }_{1}=2 \cdot 874, P=0 \cdot 09\right)$.

Taxa comprising the regional community. Fourteen species of helminths were recorded in total, 8 nematodes and 6 cestodes (Tables 2 and 3), 11 in 1999 and 13 in 2002. Of these 1 nematode species was recorded in 1999 (Trichuris sp.) but not in 2002, and 2 (A. annulosa and Nematoda sp.) in 2002 but not 1999 . One species of larval cestode $(C$. globifera $)$ was recorded in 2002 but not in 1999 (Table 2 and for further details see Behnke et al. 2008).

The regional helminth community, combining all the data, was clearly dominated by nematodes which accounted for $90.7 \%$ of all the helminths (68.6\% when $S$. petrusewiczi was excluded). Larval 
Table 2. Presence or absence of helminth species by site and year

\begin{tabular}{|c|c|c|c|c|c|}
\hline \multirow[b]{2}{*}{ Taxon } & \multirow[b]{2}{*}{ Species } & \multirow[b]{2}{*}{ Year } & \multicolumn{3}{|l|}{ Site } \\
\hline & & & Urwitałt & Tałty & Pilchy \\
\hline \multirow[t]{14}{*}{ Nematodes } & \multirow[t]{2}{*}{ Heligmosomum mixtum } & 1999 & + & + & - \\
\hline & & 2002 & + & + & - \\
\hline & \multirow[t]{2}{*}{ Heligmosomoides glareoli } & 1999 & + & + & + \\
\hline & & 2002 & + & + & + \\
\hline & \multirow[t]{2}{*}{ Syphacia petrusewiczi } & 1999 & + & + & + \\
\hline & & 2002 & + & + & - \\
\hline & \multirow{2}{*}{ Aspiculuris tetraptera } & 1999 & + & + & + \\
\hline & & 2002 & + & + & + \\
\hline & \multirow[t]{2}{*}{ Mastophorus muris } & 1999 & + & - & + \\
\hline & & 2002 & + & + & + \\
\hline & \multirow[t]{2}{*}{ Aonchotheca annulosa } & 1999 & - & - & - \\
\hline & & 2002 & + & + & - \\
\hline & \multirow[t]{2}{*}{ Trichuris sp. } & 1999 & - & - & + \\
\hline & & 2002 & - & - & - \\
\hline \multirow[t]{12}{*}{ Cestodes } & \multirow[t]{2}{*}{ Catenotaenia henttoneni } & 1999 & + & + & + \\
\hline & & 2002 & + & + & + \\
\hline & \multirow[t]{2}{*}{ Paranoplocephala omphalodes } & 1999 & + & - & - \\
\hline & & 2002 & + & + & - \\
\hline & \multirow[t]{2}{*}{ Mesocestoides lineatus } & 1999 & + & + & + \\
\hline & & 2002 & + & + & + \\
\hline & \multirow[t]{2}{*}{ Taenia martis } & 1999 & - & - & + \\
\hline & & 2002 & + & - & + \\
\hline & \multirow[t]{2}{*}{ Taenia mustelae } & 1999 & + & - & + \\
\hline & & 2002 & + & + & + \\
\hline & \multirow[t]{2}{*}{ Cladotaenia globifera } & 1999 & - & - & - \\
\hline & & 2002 & + & - & + \\
\hline
\end{tabular}

$(+$, present; - , absent.)

Table 3. Measures of component community structure by site and year of study

(The measures of component community structure listed here follow Kennedy and Hartvigsen (2000). The Berger-Parker dominance index is the proportion of all helminths sampled represented by the dominant species. The dominant species is that showing the highest proportion in each subset of data. The unbiased Simpson's index of diversity was calculated as $\left(1-\Sigma_{i} p_{i}^{2}\right) \times(n /(n-1))$ where $n=$ total number of helminths in data subset and $p$ is the proportion of the $i^{\text {th }}$ species (Lande, 1996).)

\begin{tabular}{|c|c|c|c|c|c|}
\hline & \multirow[b]{2}{*}{ Year } & \multicolumn{4}{|l|}{ Site } \\
\hline & & Urwitałt & Tałty & Pilchy & Combined \\
\hline $\begin{array}{l}\text { Total no. of helminth } \\
\text { species identified }\end{array}$ & $\begin{array}{l}1999 \\
2002 \\
\text { Combined }\end{array}$ & $\begin{array}{l}9 \\
12 \\
12\end{array}$ & $\begin{array}{l}6 \\
11 \\
\mathbf{1 1}\end{array}$ & $\begin{array}{l}9 \\
8 \\
\mathbf{1 0}\end{array}$ & $\begin{array}{l}11 \\
13 \\
\mathbf{1 4}\end{array}$ \\
\hline $\begin{array}{l}\text { Berger-Parker dominance } \\
\text { index }\end{array}$ & $\begin{array}{l}1999 \\
2002 \\
\text { Combined }\end{array}$ & $\begin{array}{l}0 \cdot 934 \\
0 \cdot 469 \\
\mathbf{0} \cdot 820\end{array}$ & $\begin{array}{l}0 \cdot 909 \\
0 \cdot 521 \\
\mathbf{0} \cdot \mathbf{7 9 4}\end{array}$ & $\begin{array}{l}0 \cdot 685 \\
0 \cdot 399 \\
\mathbf{0} \cdot \mathbf{5 5 4}\end{array}$ & $\begin{array}{l}0 \cdot 840 \\
0 \cdot 232 \\
\mathbf{0} \cdot \mathbf{7 0 5}\end{array}$ \\
\hline Dominant species & $\begin{array}{l}1999 \\
2002 \\
\text { Combined }\end{array}$ & $\begin{array}{l}S . \text { petruseziczi } \\
\text { S. petrusewiczi } \\
\text { S. petrusewiczi }\end{array}$ & $\begin{array}{l}\text { S. petrusewiczi } \\
\text { Mesocestoides } \\
\text { S. petrusewiczi }\end{array}$ & $\begin{array}{l}\text { A. tetraptera } \\
\text { A. tetraptera } \\
\text { A. tetraptera }\end{array}$ & $\begin{array}{l}\text { S. petrusewiczi } \\
\text { A. tetraptera } \\
\text { S. petrusewiczi }\end{array}$ \\
\hline Simpson's index & $\begin{array}{l}1999 \\
2002 \\
\text { Combined }\end{array}$ & $\begin{array}{l}0 \cdot 125 \\
0 \cdot 732 \\
\mathbf{0} \cdot 322\end{array}$ & $\begin{array}{l}0 \cdot 169 \\
0 \cdot 622 \\
\mathbf{0} \cdot \mathbf{3 5 3}\end{array}$ & $\begin{array}{l}0 \cdot 456 \\
0 \cdot 710 \\
\mathbf{0} \cdot 629\end{array}$ & $\begin{array}{l}0 \cdot 285 \\
0 \cdot 835 \\
\mathbf{0} \cdot 483\end{array}$ \\
\hline
\end{tabular}

cestodes accounted for $8 \cdot 1 \%$, and $1 \cdot 2 \%$ were strobilate intestinal cestodes. However, the composition changed between the 2 sampling periods. In 1999 , intestinal nematodes accounted for $98 \cdot 5 \%$ of the helminths, whereas in 2002 this figure dropped to $63 \cdot 3 \%$, and these values fell only marginally when $S$. petrusewiczi was discounted $(90 \cdot 5$ and $52.5 \%$, respectively). Accordingly, cestode larvae were more numerous in 2002 compared with 1999 ( $31.9 \%$ versus $1.4 \%$ of total helminths, respectively) 
Table 4. Percentage distribution of higher taxa by site

$(\mathrm{Sp}=$ Syphacia petrusewiczi $; \mathrm{Ml}=$ Mesocestoides lineatus $; \mathrm{Cg}=$ Cladotaenia globifera $; \mathrm{U}=\mathrm{Urwitalt} ; \mathrm{T}=\mathrm{Talty} ; \mathrm{P}=\mathrm{Pilchy}$.

\begin{tabular}{|c|c|c|c|c|c|c|c|c|c|c|}
\hline & \multirow[b]{3}{*}{ Year } & \multicolumn{9}{|c|}{ Percentage distribution by site* } \\
\hline & & \multicolumn{3}{|c|}{ All helminths } & \multicolumn{3}{|c|}{ Excluding Sp } & \multicolumn{3}{|c|}{ Excluding $\mathrm{Sp}, \mathrm{Ml}$ and $\mathrm{Cg}$} \\
\hline & & $\mathrm{U}$ & $\mathrm{T}$ & $\mathrm{P}$ & $\mathrm{U}$ & $\mathrm{T}$ & $\mathrm{P}$ & $\mathrm{U}$ & $\mathrm{T}$ & $\mathrm{P}$ \\
\hline All helminths & $\begin{array}{l}1999 \\
2002 \\
\text { Combined }\end{array}$ & $\begin{array}{l}43 \cdot 5 \\
48 \cdot 8 \\
44 \cdot 4\end{array}$ & $\begin{array}{l}50 \cdot 2 \\
25 \cdot 3 \\
44 \cdot 6\end{array}$ & $\begin{array}{r}6 \cdot 3 \\
25 \cdot 9 \\
11 \cdot 1\end{array}$ & $\begin{array}{l}20 \cdot 9 \\
33 \cdot 6 \\
28 \cdot 4\end{array}$ & $\begin{array}{l}33 \cdot 1 \\
32 \cdot 8 \\
32 \cdot 5\end{array}$ & $\begin{array}{l}46 \cdot 0 \\
33 \cdot 6 \\
39 \cdot 1\end{array}$ & $\begin{array}{l}19 \cdot 7 \\
37 \cdot 4 \\
28 \cdot 1\end{array}$ & $\begin{array}{l}29 \cdot 5 \\
26 \cdot 0 \\
26 \cdot 8\end{array}$ & $\begin{array}{l}50 \cdot 8 \\
36 \cdot 6 \\
45 \cdot 1\end{array}$ \\
\hline Intestinal nematodes & $\begin{array}{l}1999 \\
2002 \\
\text { Combined }\end{array}$ & $\begin{array}{l}43 \cdot 6 \\
57 \cdot 0 \\
45 \cdot 2\end{array}$ & $\begin{array}{l}50 \cdot 0 \\
17 \cdot 0 \\
44 \cdot 7\end{array}$ & $\begin{array}{r}6 \cdot 4 \\
26 \cdot 0 \\
10 \cdot 1\end{array}$ & $\begin{array}{l}19 \cdot 0 \\
32 \cdot 8 \\
24 \cdot 9\end{array}$ & $\begin{array}{l}29 \cdot 7 \\
26 \cdot 5 \\
27 \cdot 3\end{array}$ & $\begin{array}{l}51 \cdot 3 \\
40 \cdot 7 \\
47 \cdot 8\end{array}$ & & & \\
\hline Adult cestodes & $\begin{array}{l}1999 \\
2002 \\
\text { Combined }\end{array}$ & $\begin{array}{l}82 \cdot 0 \\
75 \cdot 3 \\
76 \cdot 2\end{array}$ & $\begin{array}{l}13 \cdot 3 \\
21 \cdot 3 \\
20 \cdot 6\end{array}$ & $\begin{array}{l}4 \cdot 7 \\
3 \cdot 4 \\
3 \cdot 2\end{array}$ & & & & & & \\
\hline Larval cestodes & $\begin{array}{l}1999 \\
2002 \\
\text { Combined }\end{array}$ & $\begin{array}{l}31 \cdot 2 \\
28 \cdot 3 \\
29 \cdot 6\end{array}$ & $\begin{array}{l}64 \cdot 4 \\
42 \cdot 6 \\
46 \cdot 8\end{array}$ & $\begin{array}{r}4 \cdot 4 \\
29 \cdot 2 \\
23 \cdot 6\end{array}$ & & & & $\begin{array}{l}26 \cdot 6 \\
38 \cdot 3 \\
38 \cdot 2\end{array}$ & $\begin{array}{c}0 \\
27 \cdot 0 \\
25 \cdot 0\end{array}$ & $\begin{array}{l}73 \cdot 4 \\
34 \cdot 6 \\
36 \cdot 8\end{array}$ \\
\hline
\end{tabular}

* Percentage distribution is based on data adjusted for sample size.

and even more so when $S$. petrusewiczi was excluded ( $47 \cdot 5 \%$ versus $9 \cdot 5 \%$ of total helminths).

\section{Measures of component community structure}

Higher taxa. Eighty nine percent of the helminths recovered were from Urwitałt and Tałty (Table 4), but whereas at Urwitalt the values were comparable in 1999 and 2002, at Talty the percentage distribution fell by half, and in 2002 a greater percentage of the helminths was recovered from Pilchy $(25.9 \%$ in 2002 versus $6 \cdot 3 \%$ in 1999). Examining the higher taxa more closely, values for intestinal nematodes, adult and larval cestodes were more stable at Urwitałt compared with Talty and Pilchy. In both years the highest percentages of adult cestodes were observed in voles from Urwitałt, and despite a fall of approximately one third, most of the larval cestodes were recovered in both years from voles from Talty.

When $S$. petrusewiczi was excluded from the data, the percentage distribution of the remaining helminths was more similar across the 3 sites in the combined data set and in 2002. However, in 1999 the situation was reversed in comparison to the earlier analysis. This time, $46 \%$ of the remaining helminths were encountered at Pilchy (rather than just $6 \cdot 3 \%$ as in the total database). Exclusion of $M$. lineatus and C. globifera changed the balance even more in favour of Pilchy in 1999 and in the combined database, although in 2002 there was little difference between Pilchy and Urwitalt. Much the same was evident for intestinal nematodes. Exclusion of $S$. petrusewiczi resulted in most remaining nematodes being attributable to voles from Pilchy.
Total species richness, dominant species and diversity indices by site. Between years, the number of helminth species recorded at Urwitalt and Talty increased by 3 and 5 , respectively and at Pilchy decreased by 1 (Table 3). Berger-Parker dominance indices were lower at all three sites in 2002 and the highest index was obtained for Tałty in 2002, compared with Urwitalt in 1999. In both years the index was lowest at Pilchy.

At both Urwitalt and Pilchy the dominant species remained the same ( $S$.petrusewiczi and A.tetraptera, respectively) but at Talty Mesocestoides sp. replaced $S$. petrusewiczi in 2002 (Table 3). Because the communities were less dominated by the oxyuroid nematodes in 2002 compared with 1999, and with the additional species recovered at 2 sites, Simpson's indices of diversity were higher in 2002, overall and at each site.

Similarity indices. Table 5 shows the values calculated for Sale's and Jaccard's similarity indices. Jaccard's index, which is based on presence/absence data, varied less (range $=0 \cdot 44-0 \cdot 81$ ) than Sale's index, which takes relative abundance of species into consideration.

The greatest similarity in Jaccard's index was between Urwitalt in both years (1999 and 2002) and between Urwitalt 1999 and Talty in both 1999, between Urwitalt and Talty in 2002, and 2002 and also between these two sites with years combined. Values for Pilchy were generally lower irrespective of the comparison. When $S$. petrusewiczi, M. lineatus and $C$. globifera were excluded the index changed very little in most cases, a reflection of the fact that these species were relatively rare in the population. 
Table 5. Sale's and Jaccard's similarity indices between sites and in each of the years, between sites with years combined, and between years with sites combined

(Data are given for all helminths, and separately after exclusion of S. petrusewiczi (Sp), M. lineatus (Ml) and C.globifera $(\mathrm{Cg})$.)

\begin{tabular}{|c|c|c|c|c|c|c|c|c|c|c|c|c|c|c|}
\hline & \multicolumn{7}{|c|}{ Sale's Similarity Index } & \multicolumn{7}{|c|}{ Jaccard's Similarity Index } \\
\hline & U02 & T99 & T02 & P99 & $\mathrm{P} 02$ & Tc & Pc & U02 & T99 & T02 & P99 & $\mathrm{P} 02$ & Tc & Pc \\
\hline U99 & 0.54 & $0 \cdot 93$ & $0 \cdot 07$ & $0 \cdot 01$ & $0 \cdot 01$ & & & $0 \cdot 75$ & $0 \cdot 67$ & $0 \cdot 82$ & $0 \cdot 64$ & $0 \cdot 6$ & & \\
\hline U99 (excluding Sp, Ml, Cg) & $(0 \cdot 34)$ & $(0 \cdot 15)$ & $(0 \cdot 27)$ & $(0 \cdot 05)$ & $(0 \cdot 05)$ & & & $(0 \cdot 78)$ & $(0 \cdot 57)$ & $(0 \cdot 78)$ & $(0 \cdot 56)$ & $(0 \cdot 71)$ & & \\
\hline U02 & & $0 \cdot 56$ & $0 \cdot 28$ & $0 \cdot 14$ & $0 \cdot 34$ & & & & $0 \cdot 5$ & $0 \cdot 77$ & $0 \cdot 62$ & $0 \cdot 58$ & & \\
\hline U02 (excluding Sp, Ml, Cg) & & $(0 \cdot 43)$ & $(0 \cdot 62)$ & $(0 \cdot 32)$ & $(0 \cdot 50)$ & & & & $(0 \cdot 44)$ & $(0 \cdot 8)$ & $(0 \cdot 6)$ & $(0 \cdot 56)$ & & \\
\hline Т99 & & & 0.09 & $0 \cdot 07$ & $0 \cdot 08$ & & & & & $0 \cdot 55$ & $0 \cdot 5$ & $0 \cdot 44$ & & \\
\hline T99 (excluding Sp, Ml, Cg) & & & $(0 \cdot 79)$ & $(0 \cdot 70)$ & $(0 \cdot 61)$ & & & & & $(0 \cdot 44)$ & $(0 \cdot 38)$ & $(0 \cdot 5)$ & & \\
\hline Т02 & & & & $0 \cdot 32$ & $0 \cdot 35$ & & & & & & $0 \cdot 54$ & $0 \cdot 5$ & & \\
\hline T02 (excluding Sp, Ml, Cg) & & & & $(0 \cdot 66)$ & $(0 \cdot 65)$ & & & & & & $(0 \cdot 45)$ & $(0 \cdot 56)$ & & \\
\hline P99 & & & & & 0.53 & & & & & & & $0 \cdot 6$ & & \\
\hline P99 (excluding Sp, Ml, Cg) & & & & & $(0 \cdot 78)$ & & & & & & & $(0 \cdot 71)$ & & \\
\hline Uc & & & & & & $0 \cdot 87$ & $0 \cdot 10$ & & & & & & $0 \cdot 77$ & $0 \cdot 69$ \\
\hline Uc (excluding $\mathrm{Sp}, \mathrm{Ml}, \mathrm{Cg}$ ) & & & & & & $(0 \cdot 43)$ & $(0 \cdot 31)$ & & & & & & $(0 \cdot 8)$ & $(0 \cdot 6)$ \\
\hline Tc & & & & & & & $0 \cdot 11$ & & & & & & & $0 \cdot 5$ \\
\hline Tc (excluding Sp, Ml, Cg) & & & & & & & $(0 \cdot 68)$ & & & & & & & $(0 \cdot 45)$ \\
\hline 99 vs 02 & & $0 \cdot 39$ & & & & & & & & $0 \cdot 71$ & & & & \\
\hline 99 vs 02 (excluding $\mathrm{Sp}, \mathrm{Ml}, \mathrm{Cg}$ ) & & $(0 \cdot 73)$ & & & & & & & & $(0 \cdot 73)$ & & & & \\
\hline
\end{tabular}

$\mathrm{U}=$ Urwitalt $\mathrm{T}=$ Tałty $\mathrm{P}=$ Pilchy $; 99=1999 ; 02=2002 ; \mathrm{Uc}=$ Urwitalt with years combined $; \mathrm{Tc}=$ Talty with years combined $; \mathrm{Pc}=\mathrm{Pilchy}$ with years combined. Comparisons of individual sites between 1999 and 2002 are highlighted in bold. 

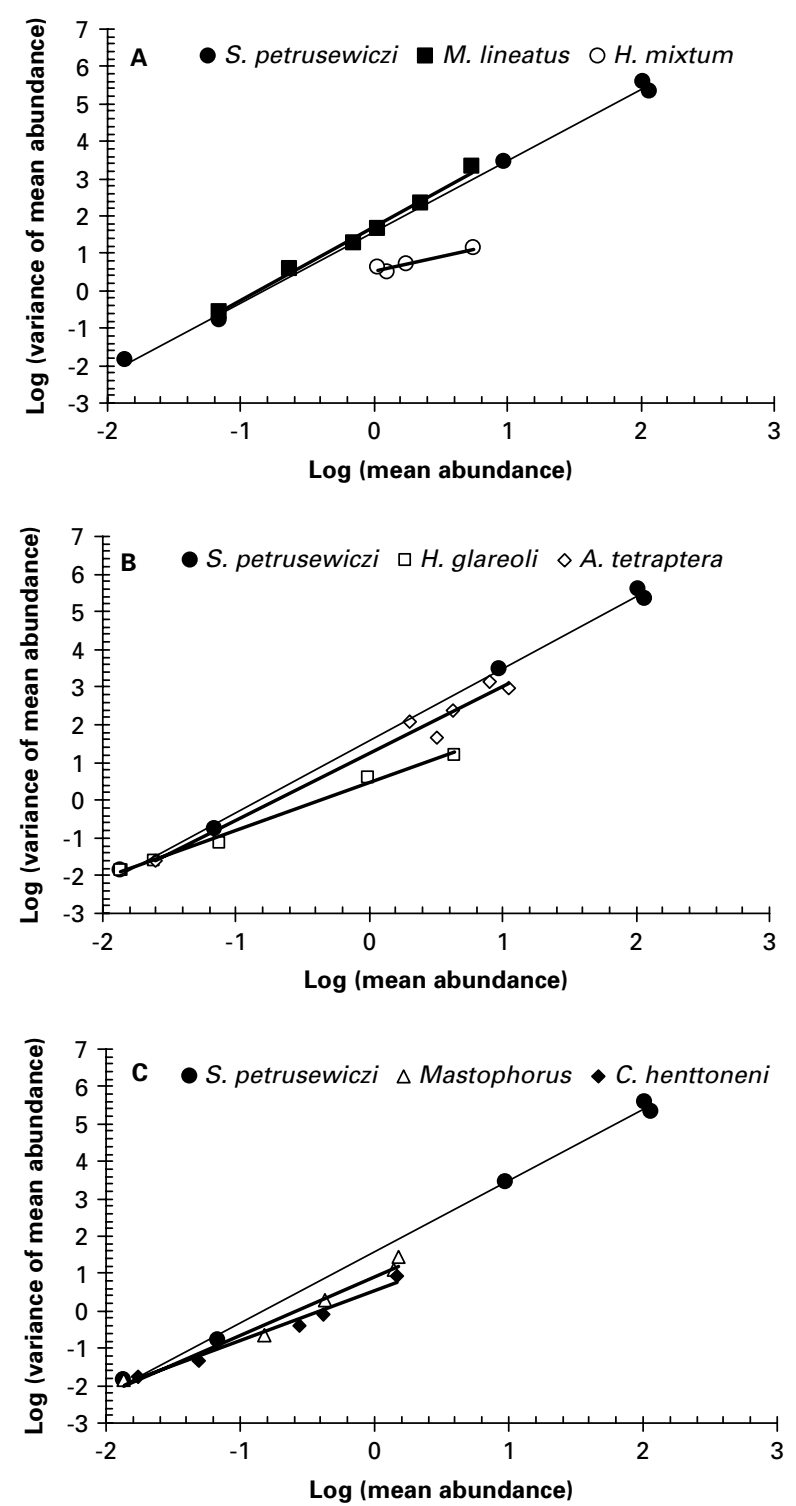

Fig. 1. Taylor's power relationship for the most prevalent species in the study. The figures show the relationships between the log-transformed variance of abundance and log transformed abundance for each of 7 species. The relationship for Syphacia petrusewicz $i$ is shown for reference in each figure. The other species are as shown in the embedded legend. For statistical analysis see Table 4 .

Sale's index showed markedly greater changes, ranging from $0 \cdot 01$ to $0 \cdot 93$. Between years, Sale's index was very similar and midrange at Urwitalt and Pilchy, but dropped markedly at Tałty. Urwitałt and Tałty were very similar in 1999 , but following the change at Talty between the years, far less so in 2002, Sale's index dropping from 0.93 to 0.28 . Nevertheless, with years combined Urwitalt and Talty were very similar but quite different from Pilchy. When S. petrusewiczi, M. lineatus and $C$. globifera were excluded the index changed quite dramatically in most cases, emphasizing that despite their low prevalence in the population, these helminths had an enormous influence on the index. The greatest similarity was between Talty and Pilchy, both of which now generated a much higher index for the comparison between years.

\section{Relationship between variance and mean abundance for the most prevalent taxa}

The data suggest that $S$. petrusewiczi and the larval cestodes, $M$. lineatus and $C$. globifera, have the greatest influence on the indicators of community structure both at the local regional fauna level and the component community level. Therefore we examined the relationship between the logarithms of the means of abundance and logarithms of the variances of abundance (Taylor, 1961) with these species ( $C$. globifera could not be tested because of insufficient degrees of freedom since it was encountered only in 2 sites in 2002, but not at all in 1999) and compared these to the slopes for this relationship generated for the other prevalent species. We expected $S$. petrusewiczi and M. lineatus to show the steepest relationships with the highest values for the slope $(b)$. The results are summarized in Fig. 1 and the statistical analysis is given in Table 6, and these show that the slope of the regression of $\log$ variance of the mean abundance of $M$. lineatus on $\log$ mean abundance was steeper than that of any of the other species. S. petrusewiczi had a very similar slope, both just less than 2. The shallowest slopes were those of $H$. mixtum and $H$. glareoli, and only the former among these two generated a slope less than 1. It is worth noting that a slope of less than 1 for Taylor's Power Law indicates an under-dispersed, uniform distribution, unusual for a parasitic organism.

\section{DISCUSSION}

The data and the analysis presented in this paper show that the majority of the indicators of regional helminth fauna and component community structure were remarkably fluid, with substantial variation between the 2 years. Given the evidence that there is some stability of the more common species in the medium-term at the infracommunity level (Bajer et al. 2005 ; Behnke et al. 2008), and our expectations for stability at the higher levels of community organization (regional and component communities; see Introduction section), this was not what we had expected. The temporal variability of the derived values utilized in this and in other studies (Montgomery and Montgomery, 1990) to summarize regional and component community structure is therefore of fundamental interest, and raises the question of whether they serve any useful purpose. It is pertinent to assess next the species that were primarily responsible for temporal instability of the key measures. 
Table 6. Taylor's power law relationships for the most prevalent species in the study

(For each species the log of the variance of the mean abundance was regressed on the log of the mean abundance, with data calculated separately for each of the three sites in each of 2 years, hence maximum $n=6$. However, because in some subsets of data specific parasites were not found (prevalence $=0 \%$ ) these subsets were excluded, and for this reason the degrees of freedom fall below 4 in some cases.)

\begin{tabular}{|c|c|c|c|c|c|c|c|}
\hline \multirow[b]{2}{*}{ Species } & \multicolumn{2}{|l|}{ Regression } & \multicolumn{4}{|c|}{ ANOVA } & \multirow{2}{*}{$\begin{array}{l}\text { t-test for } \\
\text { slope* } \\
t\end{array}$} \\
\hline & Slope $(b) \pm$ & S.E.M. & $F$ & D.F.† & $r^{2}$ & $P$ & \\
\hline M. lineatus & $1 \cdot 972$ & $0 \cdot 094$ & $437 \cdot 8$ & 1,4 & $0 \cdot 989$ & $<0.001$ & $20 \cdot 9$ \\
\hline S. petrusewiczi & 1.906 & 0.051 & $1415 \cdot 9$ & 1,3 & 0.997 & $<0.001$ & $37 \cdot 6$ \\
\hline A. tetraptera & 1.776 & $0 \cdot 158$ & $127 \cdot 0$ & 1,4 & 0.962 & $<0.001$ & $11 \cdot 3$ \\
\hline M. muris & $1 \cdot 572$ & $0 \cdot 131$ & $143 \cdot 8$ & 1,3 & 0.973 & 0.001 & $12 \cdot 0$ \\
\hline C. henttoneni & $1 \cdot 324$ & $0 \cdot 124$ & $113 \cdot 2$ & 1,4 & 0.957 & $<0.001$ & $10 \cdot 6$ \\
\hline H. glareoli & $1 \cdot 269$ & 0.054 & $548 \cdot 0$ & 1,4 & 0.991 & $<0.001$ & $23 \cdot 4$ \\
\hline H. mixtum & 0.794 & $0 \cdot 173$ & $21 \cdot 0$ & 1,2 & $0 \cdot 869$ & $0 \cdot 045$ & $4 \cdot 58$ \\
\hline
\end{tabular}

* Test of slope greater than zero.

$\dagger$ Degrees of freedom.

At the core of this between-year variation were 3 species, the oxyuroid $S$. petrusewiczi and two cestodes, $M$. lineatus and $C$. globifera, that exploit bank voles as their intermediate hosts. All 3 species show low to modest prevalence in the bank voles in the region (Behnke et al. 2001; Bajer et al. 2005) and elsewhere (Le Pesteur et al. 1992; Haukisalmi and Henttonen, 1993), but when they do occur their numbers can be extremely high. This was reflected in this study in the highest gradients for Taylor's Power Law relationship, and in the case of $S$. petrusewiczi the low values of $k$, the aggregation constant, and high indices of dispersion and discrepancy (see accompanying paper, Behnke et al. 2008).

The highest individual worm burden recorded for $S$. petrusewiczi in this study was 4026 worms (mature male vole from Urwitałt in 1999), this one vole accounting for $29 \cdot 8 \%$ of all the helminths recovered from the 358 voles in the study. Although not common, in our experience such heavily infected animals are not rare either. In another study we reported a bank vole with 6130 worms of this species (Bajer et al. 2005). In fact, in the current study, only 25 voles were infected and of these 8 had worm burdens in the range 181 to 4026 . Thus, although prevalence was low (Behnke et al. 2008) S. petrusewiczi nevertheless contributed substantially to total worm burdens and the Berger-Parker index, Sale's similarity index and, as can be seen from Table 3, figured prominently among the dominant species by this criterion. Bajer et al. (2005) discussed some of the underlying factors that are responsible for this aggregation of worms in specific hosts. Syphacia spp. females migrate through the intestine when fully gravid and emerge through the anal sphincter to lay their eggs in large batches on the peri-anal surface. Since the eggs are rapidly infective, transmission most probably relies on close contact between animals, for example when sleeping in family groups in their nests and allogrooming, and if one individual becomes infected through contact with voles from outside social groups, the worms spread rapidly through the remainder of the group, particularly among naïve juveniles (Lewis, 1987). There is also some evidence that prevalence and abundance of Syphacia spp. increase when the population density is high and fall when it is low (Lewis, 1968; Kisielewska, $1970 a$; Montgomery and Montgomery, 1988; Haukisalmi and Henttonen, 1990), and the substantial drop in the prevalence of $S$. petrusewiczi between 1999 (when vole densities were very high; 18.8/1000 trap hours at Urwitalt, see Bajer et al. 2001 ) and 2002 (when they were lower at $8 \cdot 6,8 \cdot 1$ and 15·7/1000 trap hours at Urwitałt, Tałty and Pilchy respectively; Behnke et al. unpublished data) is consistent with this view. Because $S$. petrusewiczi were aggregated in just a few hosts in large numbers, they had a major impact on indicators of regional fauna and component community structure. When prevalence and abundance were high, such as in 1999, the influence of $S$. petrusewiczi on diversity indices was so overwhelming that other species hardly contributed to the calculations, generating Berger-Parker dominance indices above 0.9 (i.e. dominant species accounting for more than $90 \%$ of all worms) and correspondingly low Simpson's indices of diversity. Thus the absence of any animals heavily infected with $S$. petrusewiczi in 2002 (the heaviest infection was 388) was mainly responsible for the substantial drop in mean helminth burdens between the two years of our study, fall in the Berger-Parker dominance index and increase in Simpson's ID, illustrating how derived summary statistics such as those commonly used as measures of component community structure can be easily biased to give an illusion of major change.

The two cestodes exploit bank voles as intermediate hosts, but as far as is known, neither replicates asexually in these hosts (Loos-Frank, 1980 b) as some other cestodes, including Mesocestoides corti, 
are known to do (Specht and Voge, 1965; Chernin and McLaren, 1983). Although we have seen many infected animals, we have never encountered dividing forms and this is consistent with the findings of Loos-Frank $(1980 \mathrm{~b})$. It is worth also drawing attention here to the controversy about the species of Mesocestoides in bank voles in the region. A second species, $M$. leptodactylus was described by LoosFrank $(1980 a)$ and shown to be the species infecting voles in Germany (Loos-Frank, 1980 b). However, it was considered nomen dubium by Premier (1983) and Tenora (2004) and we have chosen to refer to it by its original name $M$. lineatus. The definitive hosts for M. lineatus are wild carnivores and the most likely host is the fox (Vulpes vulpes), although raccoon dogs (Nyctereutes procyonoides) also inhabit the forests where we trapped. Rodents probably become infected with $M$. lineatus when they feed on oribatid mites that in turn must get infected by feeding on contaminated food or directly on the faeces of the definitive host, although the role of a first intermediate host in the life-cycle of this species is still not fully resolved (Loos-Frank, 1991). M. lineatus was rare in our voles, affecting just 8 out of the 358 voles, but the heavy infections, 4 of which were in the range 35-393 (and total number of worms recovered $=612$ ), had a disproportionate influence on summary statistics for the subsets of voles to which they belonged. C. globifera matures in owls and raptors such as kestrels, hawks and buzzards (Ferrer et al. 2004), for which bank voles are a major dietary component. Heavy infections in voles (2 infected animals harbouring 200 and 250 larvae respectively) are probably attributable to the consumption of large batches of transmission stages on just one occasion, probably through feeding on bird faeces or vegetation heavily contaminated with eggs from freshly deposited faeces. Parasite burdens with these species were not as numerous as those with $S$. petrusewiczi (Behnke et al. 2008), and both were more common in 2002, partly compensating for the loss of $S$. petrusewiczi in that year.

Another species that had some effect on summary measures was $A$.tetraptera. This species is normally considered to be a parasite of Mus domesticus and M. musculus (Behnke, 1975, 1976), but it has also been recorded from bank voles elsewhere (Sharpe, 1964). Experimental data show that $M$. glareolus cannot be easily infected with eggs derived from M. musculus (Behnke, 1974), and so it is possible that the form in bank voles is a cryptic species not yet clearly differentiated from that infecting Mus spp. However, we are not aware of any molecular genetic studies characterizing Aspiculuris spp. and comparing isolates from M. glareolus and Mus spp. The prevalence of $A$. tetraptera also increased from 1999 to 2002, but curiously the abundance fell overall (Behnke et al. 2008), and we have data that suggest a long-term trend of rising prevalence of this species across several years (Bajer et al. unpublished). As the accompanying paper shows (Behnke et al. 2008) the prevalence of $A$. tetraptera remained stable at about $58 \%$ at Pilchy, but increased markedly at both Urwitalt and Talty. Thus, in addition to the major fluctuations in summary statistics caused by $S$. petrusewicz $i$ and the two cestodes, there is also a slower long-term trend reflected in the increasing importance of this species in the component community structure of bank voles in our study sites.

Underlying the dramatic changes associated with $S$. petrusewicz $i$ and the slower long-term change with A. tetraptera, there are also changes in prevalence and abundance of the more stable core species, such as $H$. mixtum and $H$. glareoli, and for both of these site effects are more important than temporal ones (see Behnke et al. 2008).

Although most of the summary statistics reflecting regional and component community structure could not be tested statistically, it is evident that, to a large extent, the more marked changes between the years were driven by the disproportionate influence of $S$. petrusewiczi, M. lineatus and C. globifera. In contrast, the core species provided an element of underlying stability in the summary indices between years and the sporadic occurrence of the other rare species probably made little difference to these calculations other than by contributing to species richness at regional helminth fauna and component community levels. Whilst the range of rarer species in any given location can be eventually assessed comprehensively, it requires large sample sizes since species richness at the community level is dependent on sample size (Walther et al. 1995: Dove and Cribb, 2006). To a large extent these rare species are not specific to bank voles and their transmission is dependent on the presence of other hosts in the vicinity. Taenia martis and T. mustelae are both parasites of mustelids (Verster, 1969; Loos-Frank, 2000), and their population sizes and worm burdens determine the risk of infection for voles, which act as intermediate hosts. Both hosts are highly mobile mammals, and their populations probably show marked fluctuations in specific woodlands, but when they are present they contribute infective stages of the tapeworms they harbour, adding species richness at the component community level for that site.

We conclude that, with the exception of overall prevalence of helminths at the regional faunal level and Jaccard's similarity index at the component community level, other indicators of regional and component community structure in bank voles in our study sites varied considerably between years and the rank order of sites in relation to any specific measure changed unpredictably. Attention has been drawn previously to the variability in measures of helminth species richness between surveys of the same host (Poulin and Mouillot, 2004). To a large extent the variation in the derived measures reported 
in the current study was accounted for by those species of helminths that have the potential for extreme aggregation, developing exceptionally high worm burdens, or depend on the presence of vagile definitive hosts that seed the environment with transmission stages and have a greater potential than bank voles to move between sites, and hence to crosscontaminate bank vole populations. A further tier of complexity was derived from those helminth species whose prevalence in a specific component community was subject to long-term trends of increasing prevalence and abundance. Clearly the usefulness of the summary measures, reflecting regional helminth fauna and component community structure of helminths in bank voles, employed in this study was restricted to the years in which the surveys were conducted. These indices varied considerably between the two years of the surveys, and hence temporal changes confounded any site-specific characteristics at this level. On these grounds we can now reject our prediction that helminth communities in bank voles should not vary markedly between years at the regional and component community levels.

We are grateful to the M.B. Grabowski Fund for the provision of a grant for this project and the State Committee for Scientific Research (KBN), Poland and the British Council UK (BC) for additional financial support (KBN-BC Grants UM 855 and UM 930). We thank Professor M. Kozakiewicz and Dr Grzegorz Gorecki for use of the field station at Urwitałt (Department of Ecology, Institute of Zoology). We are indebted to D. Bray, T. Race, J. Dinmore, K. Frake and J. Osmond who contributed to both field and laboratory work conducted in 1999. We also thank Dr Tom Reader for his advice with statistical analyses. Finally we wish to acknowledge the support of the forestry departments responsible for the woodland sites utilized in our study (Nadleśnictwa Giżycko, Mikołajki and Orzysz).

\section{REFERENCES}

Aars, J., Ims, R. A., Liu, H. P., Mulvey, M. and Smith, M. H. (1998). Bank voles in linear habitats show restricted gene flow as revealed by mitochondrial DNA (mtDNA). Molecular Ecology 7, 1383-1389.

Abu-Madi, M. A., Behnke, J. M., Lewis, J. W. and Gilbert, F. S. (2000). Seasonal and site specific variation in the component community structure of intestinal helminths in Apodemus sylvaticus from three contrasting habitats in south-east England. Fournal of Helminthology 74, 7-16.

Alibhai, S. K. and Gipps, J. H. W. (1985). The population dynamics of bank voles. In The Ecology of Woodland Rodents Bank Voles and Wood Mice. Symposia of the Zoological Society of London, 55, 277-313. The Zoological Society of London, Clarendon Press, Oxford.

Bajer, A., Pawelczyk, A., Behnke, J. M., Gilbert, F. S. and Siński, E. (2001). Factors affecting the haemoparasitic component community structure in bank voles (Clethrionomys glareolus) from the Mazury lake district region of Poland. Parasitology 122, 43-54.
Bajer, A., Behnke, J. M., Pawełczyk, A., Kuliś, K., Sereda, M. J. and Siński, E. (2005). Medium-term temporal stability of the helminth component community structure in bank voles (Clethrionomys glareolus) from the Mazury Lake District region of Poland. Parasitology 130, 213-228.

Behnke, J. M. (1974). The Biology of Aspiculuris tetraptera (Schulz). Ph.D. thesis, University of London.

Behnke, J. M. (1975). Aspiculuris tetraptera in wild Mus musculus. The prevalence of infection in male and female mice. Fournal of Helminthology 49, 85-90.

Behnke, J. M. (1976). Aspiculuris tetraptera in wild Mus musculus. Age resistance and acquired immunity. Fournal of Helminthology 50, 197-202.

Behnke, J. M., Bajer, A., Harris, P., Newington, L., Pidgeon, E., Rowlands, G., Sheriff, C., KuliśMalkowska, K., Siński, E., Gilbert, F. S. and Barnard, C. J. (2008). Temporal and between-site variation in helminth communities of bank voles (Myodes glareolus) from N.E. Poland. 2. The infracommunity level. Parasitology 135.

Behnke, J. M., Barnard, C. J., Bajer, A., Bray, D., Dinmore, J., Frake, K., Osmond, J., Race, T. and Siński, E. (2001). Variation in the helminth community structure in bank voles (Clethrionomys glareolus) from three comparable localities in the Mazury Lake District region of Poland. Parasitology 123, 401-414.

Behnke, J. M., Harris, P. D., Bajer, A., Barnard, C. J., Sherif, N., Cliffe, L., Hurst, J., Lamb, M., Rhodes, A., James, M., Clifford, S., Gilbert, F. S. and Zalat, S. (2004). Variation in the helminth community structure in spiny mice (Acomys dimidiatus) from four montane wadis in the St Katherine region of the Sinai Peninsula in Egypt. Parasitology 129, 379-398.

Calvete, C., Blanco-Aguiar, J. A., Virgós, E., CabezasDiaz, S. and Villafuerte, R. (2004) Spatial variation in helminth community structure in the red-legged partridge (Alectoris rufa L.) : effects of definitive host density. Parasitology 129, 101-113.

Carleton, M. D., Musser, G. G. and Pavlinov, I.A. (2003). Myodes Pallas, 1811, is the valid name for the genus of red-backed voles. In Systematics, Phylogeny and Paleontology of Small Mammals. Proceedings of the International Conference devoted to the 90th anniversary of Prof. I.M. Gromov, November 2003, Saint Petersburg (ed. Averianov, A. and Abramson, N.), pp. 96-98.

Chernin, J. and McLaren, D. J. (1983). The pathology induced in laboratory rats by metacestodes of Taenia crassiceps and Mesocestoides corti (Cestoda). Parasitology 87, 279-287.

Corbet, G. B. (1978). Mammals of the Palaearctic Region: A Taxonomic Review. British Museum (Natural History), London.

Dove, A. D. M. and Cribb, T. H. (2006). Species accumulation curves and their applications in parasite ecology. Trends in Parasitology 22, 568-574.

Esch, G. W., Bush, A. O. and Aho, J. M. (1990). Parasite Communities: Patterns and Processes. Chapman and Hall, London.

Eira, C., Torres, J., Vingada, J. and Miquel, J. (2006). Ecological aspects influencing the helminth community 
of the wood mouse Apodemus sylvaticus in Dunas de Mira, Portugal. Acta Parasitologica 51, 300-308.

Ferrer, D., Molina, R., Adelantado, C. and Kinsella, J. M. (2004). Helminths isolated from the digestive tract of diurnal raptors in Catalonia, Spain. Veterinary Record 154, 17-20.

Gerlach, G. and Musolf, K. (2000). Fragmentation of landscape as a cause for genetic subdivision in bank voles. Conservation Biology 14, 1066-1074.

Gliwicz, J. and Ims, R. A. (2000). Dispersal in the bank vole. Polish Fournal of Ecology 48 (Suppl.) 51-61.

Hartvigsen, R. and Kennedy, C. R. (1993). Patterns in the composition and richness of helminth communities in brown trout, Salmo trutta, in a group of reservoirs. Fournal of Fish Biology 43, 603-615.

Haukisalmi, V. and Henttonen, H. (1990). The impact of climatic factors and host density on the long-term population dynamics of vole helminths. Oecologia $\mathbf{8 3}$, 309-315.

Haukisalmi, V. and Henttonen, H. (1993). Coexistence in helminths of the bank vole Clethrionomys glareolus. I. Patterns of co-occurrence. Fournal of Animal Ecology 62, 221-229.

Haukisalmi, V., Henttonen, H. and Tenora, F. (1987). Parasitism by helminths in the grey-sided vole (Clethrionomys rufocanus) in northern Finland: influence of density, habitat and sex of the host. Fournal of Wildlife Diseases 23, 233-241.

Kennedy, C. R. and Hartvigsen, R. A. (2000). Richness and diversity of intestinal metazoan communities in brown trout Salmo trutta compared to those of eels Anguilla anguilla in their European heartlands. Parasitology 121, 55-64.

Kisielewska, K. $(1970 a)$. Ecological organization of intestinal helminth groupings in Clethrionomys glareolus (Schreb.) (Rodentia). 1. Structure and seasonal dynamics of helminth groupings in a host population in the Białowieża National Park. Acta Parasitologica Polonica 18, 121-147.

Kisielewska, K. (1970b). Ecological organization of intestinal helminth groupings in Clethrionomys glareolus (Schreb.) (Rodentia). III. Structure of the helminth groupings in C. glareolus populations of various forest biocoenoses in Poland. Acta Parasitologica Polonica 18, 163-176.

Lande, R. (1996). Statistics and partitioning of species diversity, and similarity among communities. Oikos 76, 5-13.

Le Pesteur, M. H., Giraudoux, P., Delattre, P., Damange, J. P. and Quere, J. P. (1992).

Spatiotemporal distribution of four species of cestodes in a landscape of mid-altitude mountains (Jura, France). Annales de Parasitologie Humaine et Comparée 67, 155-160.

Lewis, J. W. (1968). Studies on the helminth parasites of the long-tailed field mouse, Apodemus sylvaticus sylvaticus from Wales. Fournal of Zoology, London 154, 287-312.

Lewis, J. W. (1987). Helminth parasites of British rodents and insectivores. Mammal Review 17, 81-93.

Loos-Frank, B. (1980a). Mesocestoides leptothylaceus n.sp. und das nomenklatorische Problem in der Gattung Mesocestoides Vaillant, 1863 (Cestoda,
Mesocestoididae). Tropenmedizin und Parasitologie 31, 2-14.

Loos-Frank, B. (1980b). The common vole, Microtus arvalis Pall, as the intermediate host of Mesocestoides (Cestoda) in Germany. Zeitschrift für Parasitenkunde 63, 129-136.

Loos-Frank, B. (1991). One or two intermediate hosts in the life cycle of Mesocestoides (Cyclophyllidea, Mesocestoididae)? Parasitology Research 77, 726-728.

Loos-Frank, B. (2000). An up-date of Verster's (1969) 'Taxonomic revision of the genus Taenia Linnaeus' (Cestoda) in table format. Systematic Parasitology 45, 155-183.

Montgomery, S. S. J. and Montgomery, W. I. (1988). Cyclic and non-cyclic dynamics in populations of the helminth parasites of wood mice Apodemus sylvaticus. Fournal of Helminthology 62, 78-90.

Montgomery, S. S. J. and Montgomery, W. I. (1989). Spatial and temporal variation in the infracommunity structure of helminths of Apodemus sylvaticus (Rodentia: Muridae). Parasitology 98, 145-150.

Montgomery, S. S. J. and Montgomery, W. I. (1990). Structure, stability and species interactions in helminth communities of wood mice Apodemus sylvaticus. International Fournal for Parasitology 20, 225-242.

Poulin, R. (1997). Species richness of parasite assemblages: evolution and patterns. Annual Reviews in Ecology and Systematics 28, 341-358.

Poulin, R. (2004). Macroecological patterns of species richness in parasite assemblages. Basic and Applied Ecology 5, 423-434.

Poulin, R. (2007). Are there general laws in parasite ecology? Parasitology 134, 763-776.

Poulin, R. and Mouillot, D. (2004). The evolution of taxonomic diversity in helminth assemblages of mammalian hosts. Evolutionary Ecology 18, 231-247.

Premier, J. (1983). On the problem of European Mesocestoides species (Cestoda) from mammals. Helminthologia 20, 89-95.

Pucek, Z., Ryszkowski, L. and Zejda, J. (1969). Estimation of average length of life in bank vole, Clethrionomys glareolus (Schreber, 1780). In Energy Flow Through Small Mammal Populations (ed. Petrusewicz, K. and Ryszkowski, L.), pp. 137-210. Polish Scientific Publications, Warszawa.

Rohlf, F. J. and Sokal, R. R. (1995). Statistical Tables. W.H. Freeman and Company, San Francisco.

Sharpe, G. I. (1964). The helminth parasites of some small mammal communities. I. The parasites and their hosts. Parasitology 54, 145-154.

Smal, C. M. and Fairley, J. S. (1984). The spread of the bank vole Clethrionomys glareolus in Ireland. Mammal Review 14, 71-78.

Specht, D. and Voge, M. (1965). Asexual multiplication of Mesocestoides tetrathyridia in laboratory animals. Fournal of Parasitology 51, 268-272.

Spitzenberger, F. (1999). Clethrionomys glareolus. In The Atlas of European Mammals (ed. Mitchell-Jones, A. J., Amori, G., Bogdanowicz, W., Krystufek, B., Reijnders, P. J. H., Spizenberger, F., Stubbe, M., Thissen, J. B. M., Vohralik, V. and Zima, J.), pp. 212-213. Academic Press, London. 
Taylor, L. R. (1961). Aggregation, variance and the mean. Nature, London 189, 732-735.

Tenora, F. (2004). Notes to Mesocestoides Vaillant, 1863 (Cestoda) and findings of Mesocestoides sp. parasitizing Canis familiaris (Carnivora) in the Czech Republic. Acta Universitatis Agriculturae et Silviculturae Mendelianae Brunensis 52, 25-33.

Tenora, F. and Stanek, M. (1995). Changes of the helminthofauna in several Muridae and Arvicolidae at Lednice in Moravia. II. Ecology. Acta Universitatis Agriculturae et Silviculturae Mendelianae Brunensis 43, 57-65.

Timi, J. T. and Poulin, R. (2003). Parasite community structure within and across host populations of a marine pelagic fish: how repeatable is it? International Fournal for Parasitology 33, 1353-1362.
Van Apeldoorn, R. C., Oostenbrink, W. T., van Winden, A. and van der Zee, F. F. (1992). Effects of habitat fragmentation on the bank vole, Clethrionomys glareolus, in an agricultural landscape. Oikos $\mathbf{6 5}$, 265-274.

Verster, A. (1969). A taxonomic revision of the genus Taenia Linnaeus, 1758 S. Str. Ondersteport Fournal of Veterinary Research 36, 3-58.

Walther, B. A., Cotgreave, P., Gregory, R. D., Price, R. D. and Clayton, D. H. (1995). Sampling effort and parasite species richness. Parasitology Today 11, 306-310.

Wilson, D. E. and Reeder, D. M. (2005). Mammal Species of the World. A Taxonomic and Geographic Reference. 3rd Edn. Johns Hopkins University Press, Baltimore, USA. 